\title{
Mitigating SALT-Water InTrusion Through Hiram M. ChitTenden Locks
}

\author{
By Sherrill Mausshardt ${ }^{1}$ and Glen Singleton ${ }^{2}$
}

\begin{abstract}
The Seattle metropolitan area surrounds Lake Washington, a large freshwater lake connected to the salt water of Puget Sound by an 8-mi-long ship canal with a lock-and-dam structure at the downstream end of the canal. When raising vessels from Puget Sound to lake level, a strong current of salt water flows from the lock chamber into the freshwater system resulting in two opposing water-management issues at the locks: salt-water intrusion and water conservation. Several physical structures are present to prevent salt water from propagating upstream with each lake-bound lockage. During heavy use in the summer period, these structures cannot keep up with the amount of seawater entering the freshwater system, and an additional flushing technique is required. Consequently, the U.S. Army Corps of Engineers, which manages the locks, has implemented a "miniflushing" procedure for summer months. Miniflushing is defined as any process that can be temporarily implemented as part of a lockage to minimize salt-water intrusion. Recent field experiments at the locks compare two methods of miniflushing, and a recent improvement in procedure is discussed in this paper.
\end{abstract}

\section{INTRODUCTION}

The Seattle metropolitan area surrounds Lake Washington, a large freshwater lake connected to the salt water of Puget Sound by an 8 -mi-long ship canal with a lock-and-dam structure at the downstream end of the canal. The lock and canal provide a navigational link for commercial and recreational vessels between Puget Sound and Lake Washington (see Fig. 1). When raising vessels from Puget Sound to lake level, a strong current of salt water flows from the lock chamber into the freshwater system, resulting in two opposing water-management issues at the Hiram M. Chittenden Locks: salt-water intrusion and water conservation. Salt-water intrusion upstream damages the freshwater ecosystem. Water conservation, especially during droughts, demands that minimal freshwater be used for lock exchanges and for flushing salt water from the lake. Various methods to prevent salt water from reaching the lake have been used at the locks (Seckel and Rattray 1953). A recent improvement in procedure is discussed in this paper.

The Hiram M. Chittenden Locks, operated by the U.S Army Corps of Engineers Seattle District, consists of two separate locks (Fig. 2). The smaller lock chamber, which is $46 \mathrm{~m}$ long and $9.1 \mathrm{~m}$ wide, caters to pleasure craft with up to a $5.0-\mathrm{m}$ draft. The larger lock is $252 \mathrm{~m}$ long and $24.3 \mathrm{~m}$ wide, accommodating up to 9.1-m draft ocean-going vessels. The larger lock requires about 25 times more lake water per lockage $\left(86,000 \mathrm{~m}^{3}\right)$ than the small lock $\left(3,400 \mathrm{~m}^{3}\right)$. Fig. 2 is a schematic of the lock system. A middle miter gate allows flexibility in the length of large chamber lockages. Lockages occur when gravity-driven flow through two filling culverts from the lake fills the lock chamber through 22 lateral ports along the base of each wall. In addition to operating the locks, the U.S. Army Corps of Engineers monitors the salinity upstream at various stations on an hourly real-time basis. These stations start at the lock wall and continue up the Lake Wash-

${ }^{1} \mathrm{Grad}$. Student, Harris Hydr. Lab, Univ. of Washington, Seattle, WA 98195.

-P.E., Hydr. Engr., U.S. Army Corps of Engrs., Seattle Dist., Water Mgmt. Sect., Seattle, WA 98124.

Note. Discussion open until January 1, 1996. To extend the closing date one month, a written request must be filed with the ASCE Manager of Journals. The manuscript for this technical note was submitted for review and possible publication on September 27, 1993. This technical note is part of the Journal of Waterway, Port, Coastal, and Ocean Engineering, Vol. 121, No. 4, July/August, 1995. CASCE, ISSN 0733$950 \times / 95 / 0004-0224-0227 / \$ 2.00+\$ .25$ per page. Technical Note No. 7052 . ington Ship Canal into Lake Washington (see Fig. 1) (Lake Washington 1992).

Several physical structures are present to prevent salt water from propagating upstream with each lake-bound lockage (refer to Fig. 2). A salt-water barrier placed just ahead of the large chamber's upstream gate blocks the denser salt water from propagating upstream. The barrier, which raises by filling chambers in its structure with air, is $24.4 \mathrm{~m}$ long, $0.6 \mathrm{~m}$ wide, and $6 \mathrm{~m}$ high. When the salt water gets past this barricade, most of it settles into a basin located just upstream of the chamber. A salt-water drain removes the denser salt water by siphoning it back to Puget Sound by gravity (see Fig. 2). During heavy use in the summer period, the saltwater drain cannot keep up with the amount of seawater entering the freshwater system and an additional flushing technique is required. Consequently, the U.S. Army Corps of Engineers has implemented a "miniflushing" procedure for summer months. Miniflushing is defined as any process that can be temporarily implemented as part of a lockage to minimize salt-water intrusion. Recent field experiments at the locks compared two methods of miniflushing. The first method, in which flushing occurs before an upstream lockage (i.e., "prelockage miniflushing"), had been used for years by the U.S. Army Corps of Engineers. A new method, in which flushing happens just after a lockage ("postlockage miniflushing"), was compared with the original. Both miniflushes only occur with upstream lockages.

\section{PRELOCKAGE MINIFLUSHING APPROACH}

The intent of the prelockage miniflushing method is to flush salt water upstream in the lake from a previous lockage back to Puget Sound. Doing so also dilutes the chamber water as the lake water mixes with the brackish chamber water on its way to the sea. The flushing draws water from the upstream filling culvert location. As a repressive method of preventing salt-water intrusion through locks, it requires a relatively large volume of freshwater to mix with the salt water and carry it away (Abraham et al. 1973; Abraham 1975). The method proceeds as follows: lake-bound craft are brought into the chamber and the downstream gate is closed. Freshwater is flushed from upstream of the chamber out to Puget Sound for $5 \mathrm{~min}$ by opening the upstream and downstream valves for the filling culverts (see Fig. 2). Approximately $26,800 \mathrm{~m}^{3}$ of lake water is used for this flushing. Once the flushing is complete, the downstream valve is closed so that the chamber fills. As soon as the chamber water level reaches that of the 


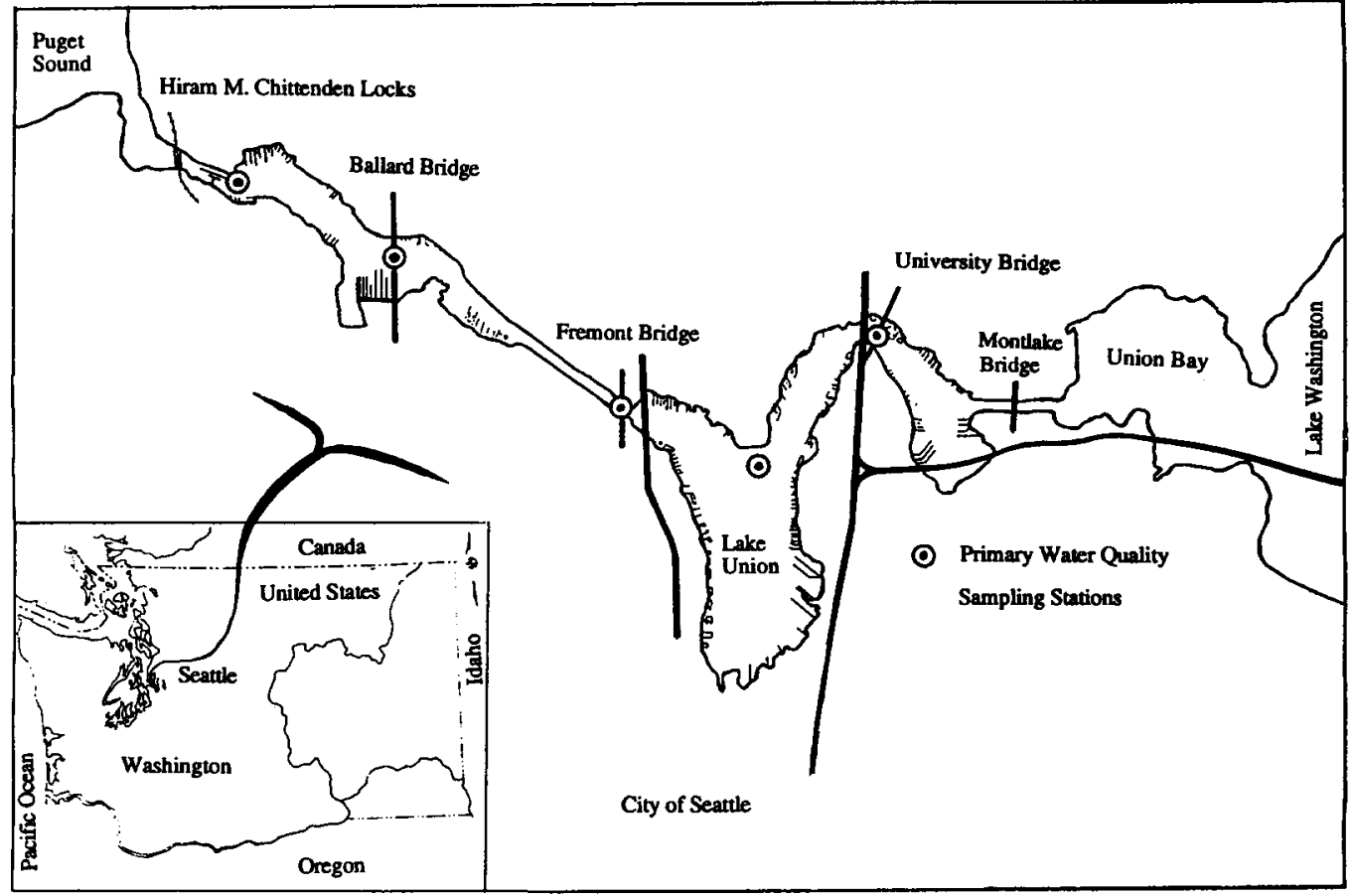

FIG. 1. Hiram M. Chittenden Locks and Surrounding Waters

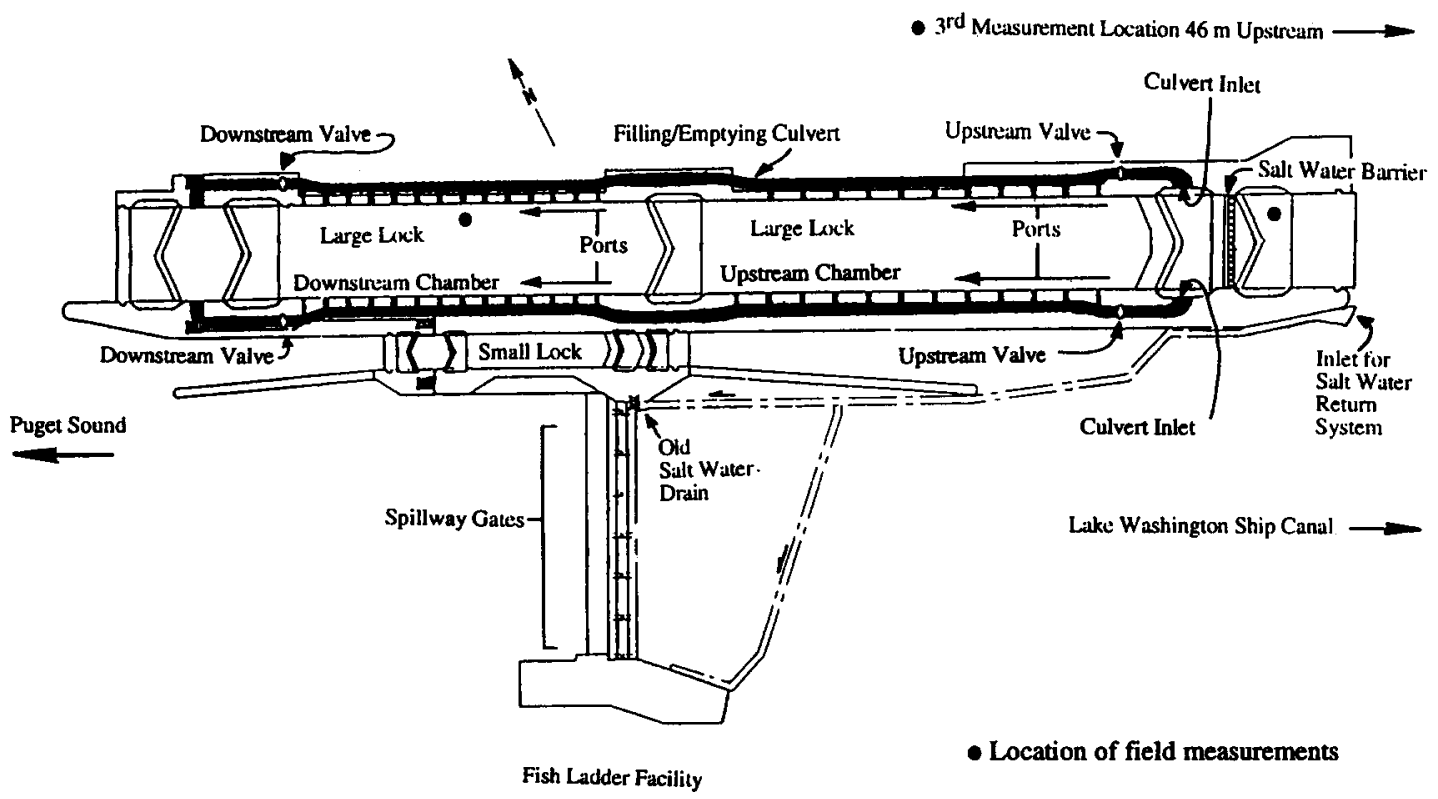

FIG. 2. Plan View of Hiram M. Chittenden Locks

lake level, the upstream gate is opened so that the boats pass to the lake.

Using the lower half of the chamber for a lockage, readings were taken at three locations along the lock wall as marked in Fig. 2. Data collected inside the chamber indicate that a minimal amount of dilution in the chamber occurred during the first 5 min of miniflushing (Fig. 3). Only after $10 \mathrm{~min}$ of miniflushing (requiring about $53,700 \mathrm{~m}^{3}$ of lake water) was there any appreciable dilution. This dilution is not worth the additional water used in flushing the chamber 10 min per lockage. The initial and final density profiles upstream of the chamber were identical: there was a considerable amount of brackish water underneath freshwater. The method neither adequately dilutes chamber water nor flushes upstream salt water back to Puget Sound.

\section{POSTLOCKAGE MINIFLUSHING APPROACH}

In postlockage miniflushing, a lockage transpires as it normally would: the lake-bound boats enter the chamber and the downstream gate closes. The chamber is raised to lake level by opening the upstream culvert valves while the downstream ones are closed. Once the chamber water level equals that of the lake, the upper gate is opened. While the upstream gate is opening, the downstream culvert valves are opened. This step flushes salt water from the bottom of the lock chamber into the side-wall ports and out into Puget Sound using approximately $50,800 \mathrm{~m}^{3}$ of lake water for a 5 -min flush. A similar means of selective withdrawal has been studied in the laboratory (Jirka and Arita 1987) and has been suggested for field use (Abraham et al. 1973). By this flushing procedure, 

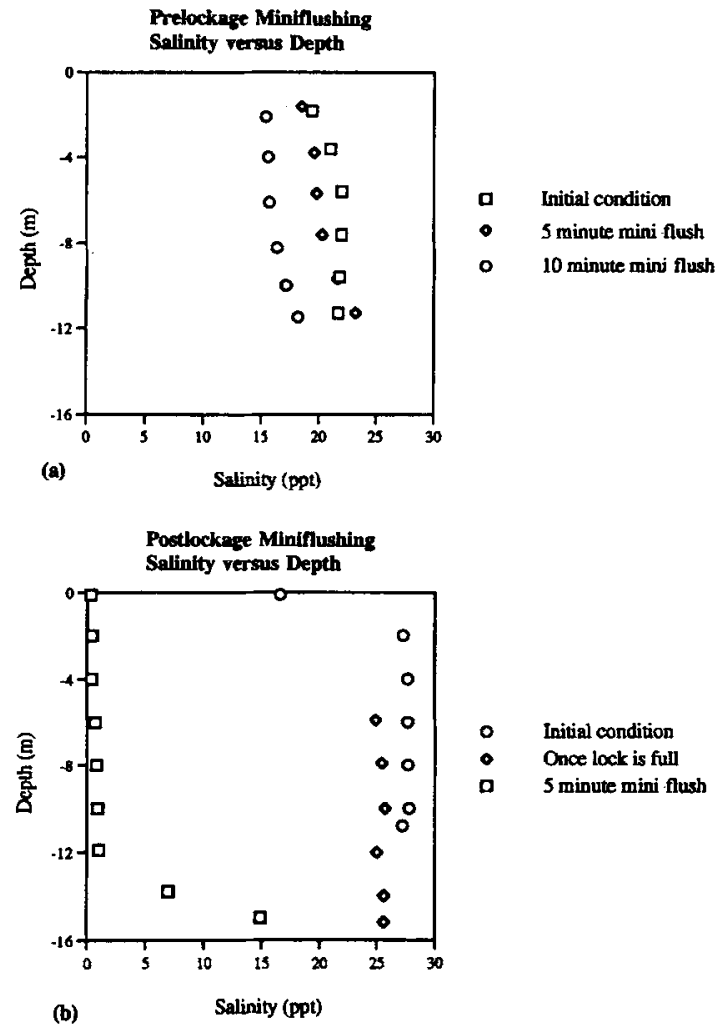

FIG. 3. Salinity versus Depth for Testing: (a) Prelockage Miniflushing; (b) Postlockage Miniflushing

the selective withdrawal of salt water during an intrusion occurs through a slot located at the base where the lock meets the adjoining freshwater basin. This method arrests the saline density current at its head, but the withdrawal cannot be completely selective and freshwater is flushed as well. The method discussed in this technical note ensures that the water withdrawn is purely salt water and the current is prevented from propagating upstream.
During experiments, the chamber was flushed out for $5 \mathrm{~min}$ before the downstream valves were closed (Fig. 3). Readings were taken at the same three locations as in the previous test: namely, in the lower chamber; at the upstream culvert intake; and 46-m upstream of the culvert intake. From the data taken at the culvert intake, it was noted that an initial slug of salt water propagates upstream before the valves are fully opened. However, the salt-water slug is small compared to the amount of salt water either flushed into Puget Sound or remaining in the lock chamber. The field measurements showed that while the prelockage miniflushing drained lake water at the culvert inlets into Puget Sound, the postlockage miniflushing arrested the upstream salt-water propagation and held it at the chamber location. Clearly, the postlockage miniflushing is an improved means of controlling the salt-water level in the lake. In mid-July, as soon as the experimental results were disseminated, a new standard operating procedure (SOP) was put into effect at the locks that instituted the postlockage miniflushing process. Because the results of the field measurements were so dramatic, the time to miniflush was decreased and stair-stepped according to which chamber would be used. For example, if the full chamber is used, then the miniflushing lasts for $5 \mathrm{~min}$, or for 3 and $2 \mathrm{~min}$, respectively, if just the upper chamber or lower chamber is used.

\section{RESULTS AND COMMENTS}

The most dramatic effect of the new process can be seen by noting the change in upstream levels of salinity for July and August of 1991 and 1992 (Figs. 4 and 5). The figures show the hourly salinity data collected below Ballard Bridge $(1.5 \mathrm{~km}$ upstream of the locks) in the Lake Washington Ship Canal and on the south lock wall of the large locks. In June and early July, there were approximately the same salinity levels at the two locations for both years. Tests began on July 10, 1992, and the new method was instituted on July 17. Once the new postlockage miniflushing technique was implemented, the salinity level drastically fell. Note that at the Ballard location, the salinity is zero for much of the summer of 1992 . The salinity only increased

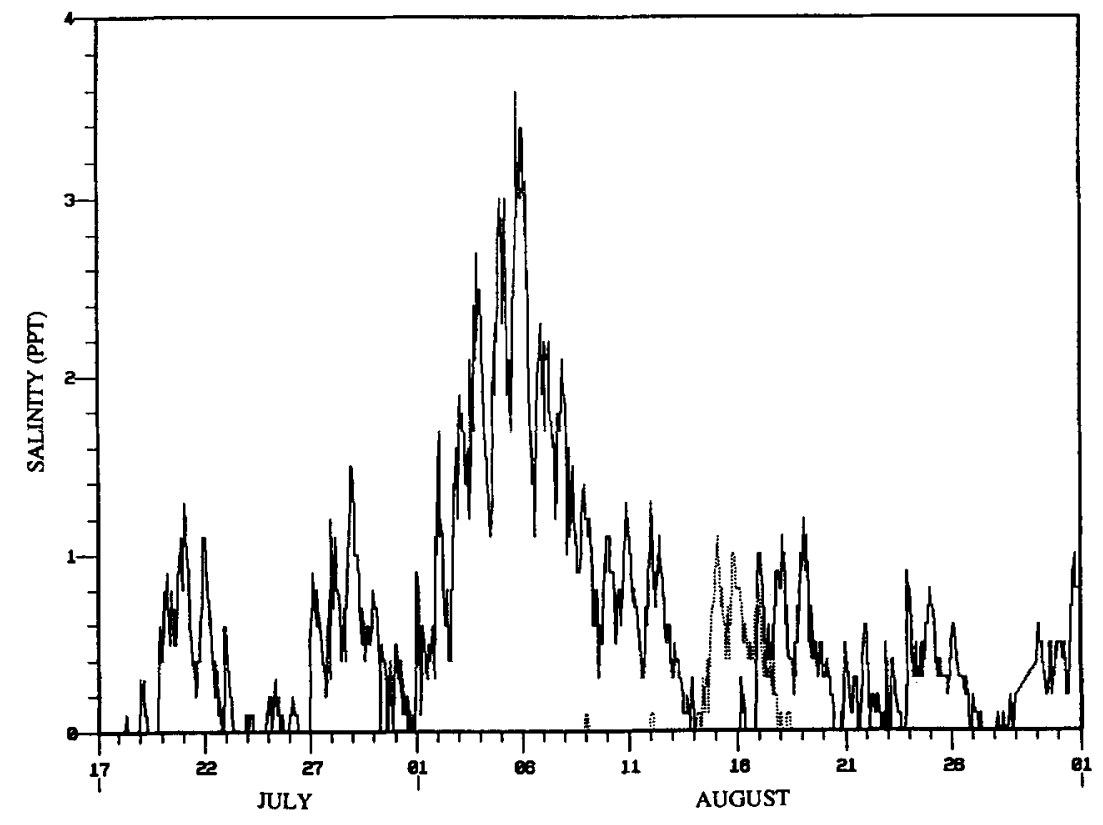

JULY - AUGUST 1991 SALINITY WITH PRE LOCKAGE MTNT FLUSHING JULY - AUGUST 1992 SALINITY WITH POST LOCKAGE MINI FLUSHING

FIG. 4. July and August Salinity Levels below Ballard Bridge for 1991 and 1992 


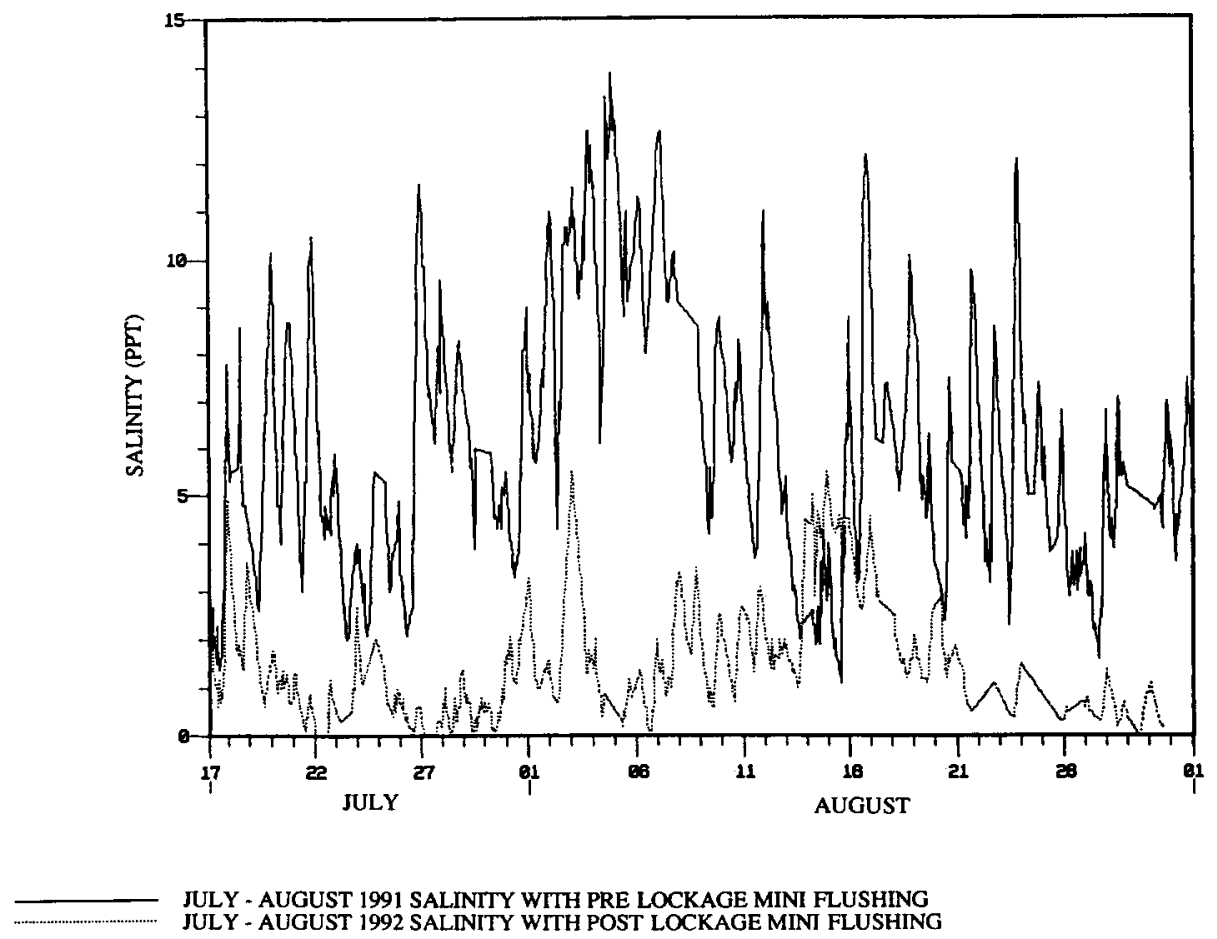

FIG. 5. July and August Salinity Levels at Large Lock for 1991 and 1992

in August after the miniflushing was stopped temporarily on August 6 and decreased again as soon as it was reinstated on August 17. Clearly, the lock master has control over salt-water buildup in the lake system by utilizing the new miniflushing technique. The new miniflushing technique also uses less freshwater by flushing for a shorter duration, which permits higher lake levels for recreation and navigation. The previous prelockage miniflushing required at least a 5min flushing period and essentially flushed out freshwater. In contrast, the new method flushes out so much salt water that the period of flushing could be dramatically reduced and the procedure implemented less frequently. Thus, the two competing issues of salt-water intrusion and water conservation are satisfied.

\section{ACKNOWLEDGMENTS}

This work was partially funded by a grant from the Washington Sea Grant Program, University of Washington, pursuant to National Oceanic and Atmospheric Administration Award No. NA36RG0071, Project
R/EP-3. Special thanks to Prof. Harry Yeh for his insights and suggestions.

\section{APPENDIX REFERENCES}

Abraham, G. (1975). "International course in hydraulic engineering: reference notes on density currents." Workshop Reference Manual. Chapter 7, Delft Hydr. Lab., Delft, The Netherlands.

Abraham, G., Van der Burgh, P., and De Vos, P. (1973) "Pneumatic barriers to reduce salt intrusion through locks." Paper No. 17, Government Publishing Ofc., The Hague, The Netherlands, 1120.

Jirka, G. H., and Arita, M. (1987). "Density currents or density wedges: boundary-layer influence and control methods." J. Fluid Mech., Vol 177, 186-206.

Lake Washington Ship Canal water control manual. (1992). U.S. Army Corps of Engrs., Seattle Dist., Seattle, Wash.

Seckel, G. R., and Rattray, M. Jr. (1953). "Studies on Lake Washington Ship Canal." Tech. Rep. No. 15, Dept. of Oceanography, Univ. of Washington, Seattle, Wash.

Stockstill, R. L., Neilson, F. M., and Zitta, V. L. (1991). "Hydraulic calculations for flow in lock manifolds." $J$. Hydr. Engrg., ASCE. 117(8), 1026-1041 